\title{
Pharmacogenomics and personalized medicine: lost in translation?
}

\author{
Jean-Sébastien Hulot*
}

\begin{abstract}
A report on the Joint Cold Spring Harbor/Wellcome

Trust Conference 'Pharmacogenomics and Personalized

Medicine', Hinxton, UK, 12-15 September 2009.
\end{abstract}

\section{Introduction}

The Sixth Joint Cold Spring Harbor/Wellcome Trust Centre Conference reported on new improvements that could affect 'personalized medicine' for the treatment of various diseases. Even though the term 'pharmacogenetics' was coined over 40 years ago, personalized medicine has become increasingly recognized in the past few years. The basic concept is to prescribe drugs according to genetic profiles or other tests that give evidence for tailoring treatments to patients, potentially improving care and saving money. It has been recognized for a long time that there is considerable inter-individual variation in the level of therapeutic responses to most drugs [1,2], and the same applies to the occurrence of adverse drug reactions. Some experts believe that most drugs currently on the market work for only a portion of the patients who take them, while countless patients are exposed to useless and/or toxic medications. This situation is a drawback of the 'one size fits all' approach of conventional phase 3 studies in which the treatment that seems to be superior on average will then be recommended for all patients with the same disease. This is a global rather than individual evaluation that determines the best treatment for a group of patients without distinguishing the fortunate few who will really benefit from it.

\section{Genome-wide association studies: a new paradigm for pharmacogenomics?}

Although individualization of certain treatments had been carried out in the pre-genomic era, recent progress

*Correspondence: jean.hulot@mssm.edu

Cardiovascular Research Center, Mount Sinai School of Medicine, One Gustave L Levy Place, Box 1030, New York, NY 10029, USA

Pharmacology department, UPMC Paris 6, Assistance Publique Hôpitaux de Paris, Hôpital Pitié-Salpêtrière, 47 Boulevard de l'hôpital, 75013 Paris, France in personalized medicine follows advances in molecular diagnostics and genomic technologies. In the past 4 years, genome-wide association studies (GWASs) have emerged as a powerful tool to identify disease-related genes for many common human disorders [3]. This hypothesis-free approach now provides useful information in the context of drug safety and efficacy. Data from the National Human Genome Research Institute (NHGRI) GWAS catalog [http://genome.gov/gwastudies] show that the number of published GWASs exceeded 400 in September 2009. Careful analysis of this catalog also reveals that the number of pharmacogenomics GWASs is beginning to accumulate, with 24 studies that have specifically examined a drug-induced phenotype and genome-wide single nucleotide polymorphism markers (Figure 1). Even if these represent less than 10\% of the overall number of studies, 15 pharmacogenomics GWASs were published during 2009. Most of these studies have succeeded in identifying associations between common genetic variants and common drug-related phenotypes, including changes in drug efficacy or occurrence of adverse drug reactions.

\section{Recent advances from pharmacogenomics GWASs}

Many new GWASs were discussed during the meeting, many focusing on the genetic determinants of response to antithrombotic agents. Stephane Bourgeois (Wellcome Trust Sanger Institute, Hinxton, UK) presented a GWAS that identified novel loci that may be implicated in patients' responses to the antithrombotic agent warfarin. These data may allow the further development of algorithms that help predict warfarin dose.

I showed data on the genetic determinants of clopidogrel response. Clopidogrel is key for prevention of arterial thrombotic complications, and it can be used in the treatment of acute coronary syndromes, ischemic cerebral infarction and established peripheral arterial disease. A recent GWAS was conducted by Shuldiner et al. [4], who administered clopidogrel to a population of 429 healthy Amish people and then genotyped the participants to identify the loss-of-function variant CYP2C19*2, which they found to be associated with a diminished biological response to the drug. They then replicated the findings in an independent sample of 227 patients 


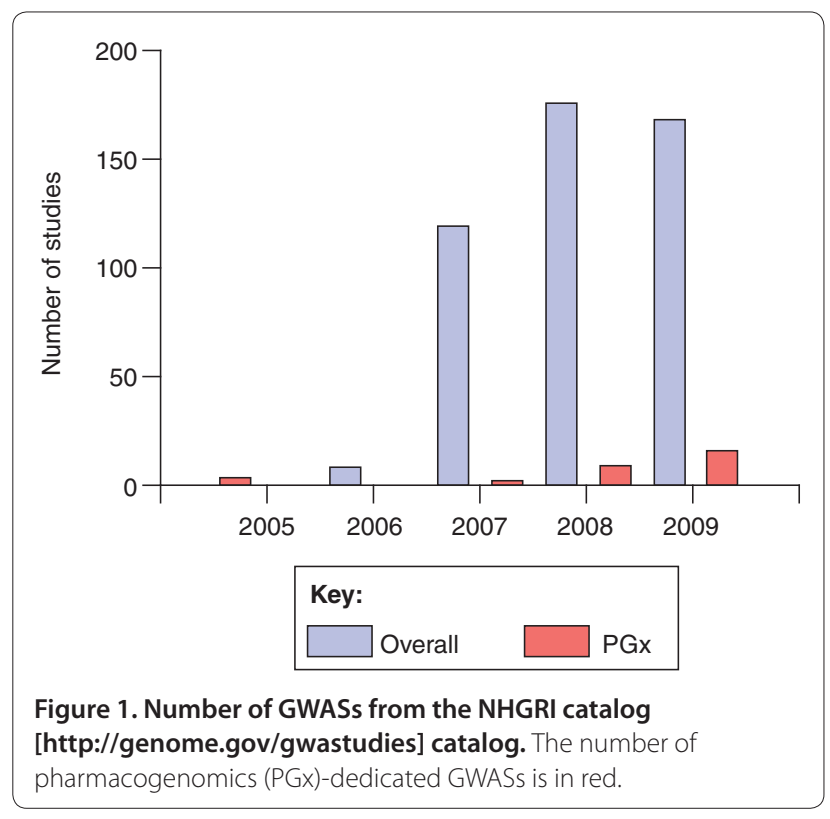

undergoing percutaneous coronary intervention and found that among those taking clopidogrel, carriers of the $C Y P 2 C 19 * 2$ variant had a 2.42 higher risk of having a cardiovascular ischemic event or of dying during the following year. The findings from this first GWAS are in agreement with previous results from candidate gene studies in this field [5-7], as presented during the meeting.

Another example concerns the occurrence of myopathy in patients treated with statins, as presented by Emma Link (Clinical Trial Service Unit and Epidemiological Studies Unit, University of Oxford, UK), Ronald Krauss (Children's Hospital Oakland Research Institute, Oakland, USA) and Bas Peters (University of Utrecht, The Netherlands). The SEARCH (Study of the Effectiveness of Additional Reductions in Cholesterol and Homocysteine) collaborative group identified 85 patients suffering from statin-induced myopathy among 12,064 post-myocardial infarction patients included in a randomized clinical trial that compared a high dose (80 $\mathrm{mg}$ ) with a low dose (20 mg) of simvastatin [8]. By performing a genome-wide analysis in 85 patients and 90 controls, they identified a strong association with a genetic variant within the SLCO1B1 gene, which encodes a transporter involved in the hepatic uptake of statins. More than $60 \%$ of the myopathy cases could be attributed to the mutated variant [8].

\section{Pharmacogenomics information is available for almost all of the best-selling drugs}

Many other examples were reported during the meeting. Concerning anti-mitotic drugs, Hiltrud Brauch (Institute of Clinical Pharmacology, Stuttgart, Germany) and William Newman (University of Manchester, UK) reported on the modulation of tamoxifen efficacy in breast cancer patients according to cytochrome p450 2D6 genetic variants. Other studies on psychotropes and anti-depressant or anti-infectious therapies (such as hypersensitivity reactions to the anti-HIV agent abacavir) were presented. These examples highlight the recent genetic discoveries that have raised the prospect of testing patients for these variants before they are prescribed drugs, so that those at risk of lack of response or of adverse drug reactions can be considered for other treatment options or careful monitoring. This new information concerns many of the most widely used drugs in the world: so far, pharmacogenomics information (and thus the perspective for personalized prescription) exists for almost all of the top ten best-selling drugs of the world (Table 1).

As pointed out by Urs Meyer (University of Basel, Switzerland), we can estimate that more than 40 pharmacogenetic conditions - that is, conditions in which variations in the sequence of a particular gene has been associated with alteration in drug response or toxicity have been described in more than one clinical study [9]. This observation is important given that 2.5 to $12 \%$ of hospital admissions and 0.4 to $0.5 \%$ of deaths are probably related to adverse drug reactions [10]. As shown by Shashi Amur (US Food and Drug Administration (FDA), Washington DC, USA) the FDA recently modified numerous drug labels to recommend or require genetic testing before drug prescription. At the same time, the FDA cleared for marketing molecular assays to promote personalized drug treatment decisions. For instance, the FDA has urged for testing for $H L A-B^{*} 5701$ before the prescription of the anti-HIV drug abacavir. It is estimated that two thirds of $H L A-B * 5701$ allele carriers (around 6\% of patients) will develop life-threatening hypersensitivity reactions. Moreover, $H L A-B * 5701$ prescreening reduced the incidence of hypersensitivity reactions to abacavir by $50 \%$ compared to a strategy without prescreening [11]. Other examples were also reported - notably, for cancer patients [12], TPMT and aziathropine, UGT1A1 and irinotecan, and others - showing the potential for personalized medicine development.

\section{Future challenges}

Despite these promising and exciting results, few pharmacogenomic biomarkers are so far in clinical use, as highlighted by Urs Meyer. This was a common theme mentioned by various researchers at the meeting: many patients that could benefit from personalized medicine do not in practice. It is as if pharmacogenomics information has been lost in the translation from scientific research to the clinical setting.

The meeting gave an opportunity to identify further obstacles on the path to the promised land of 
Table 1. Pharmacogenomics information on the top ten selling drugs in the world

\begin{tabular}{|c|c|c|c|c|c|c|}
\hline $\begin{array}{l}\text { Generic } \\
\text { name }\end{array}$ & $\begin{array}{l}\text { Therapeutic } \\
\text { class }\end{array}$ & Indications & $\begin{array}{l}\text { Genetic } \\
\text { influence? }\end{array}$ & $\begin{array}{l}\text { Drug-induced } \\
\text { phenotype }\end{array}$ & $\begin{array}{l}\text { Type of } \\
\text { studies }\end{array}$ & $\begin{array}{l}\text { Genetic } \\
\text { variant }\end{array}$ \\
\hline Atorvastatin & Statins & Dyslipidemia & Yes & Myopathy & GWAS and candidate gene & $\begin{array}{l}\text { SLCO1B1 (drug } \\
\text { transporter) }\end{array}$ \\
\hline Clopidogrel & Anti-platelet agent & Atherothombosis & Yes & $\begin{array}{l}\text { Resistance to } \\
\text { treatment }\end{array}$ & GWAS and candidate gene & $\begin{array}{l}\text { CYP2C19 (hepatic } \\
\text { enzyme) }\end{array}$ \\
\hline Esomeprazole & Proton pump inhibitor & Gastric ulcer & Yes & Drug efficacy & Candidate gene & $\begin{array}{l}\text { CYP2C19 (hepatic } \\
\text { enzyme) }\end{array}$ \\
\hline Fluticasone/Salmeterol & | Bronchodilator & Asthma & Possible & Drug efficacy & Candidate gene & $\begin{array}{l}\text { Beta-2 } \\
\text { adrenoreceptor }\end{array}$ \\
\hline Etanercept & TNF antagonist & Rheumatoid arthritis & Possible & Drug efficacy & GWAS and candidate gene & $M A F B$ \\
\hline Olanzapine & Psychotropes & Mental disorders & Yes & Drug efficacy & GWAS and candidate gene & ANKSIB; CNTNAP5 \\
\hline Risperidone & Psychotropes & Mental disorders & Yes & Drug efficacy & GWAS and candidate gene & ANKS1B; CNTNAP5 \\
\hline Darbopoetin & Erythropoetin & Anemia & $?$ & - & - & - \\
\hline Venlafaxin & Anti-depressant & Depression & Possible & Drug efficacy & Candidate gene & $\begin{array}{l}\text { CYP2D6; dopamine/ } \\
\text { serotonin transporter }\end{array}$ \\
\hline Amlodipine & Anti-hypertensive & Hypertensive & $?$ & Drug efficacy & Candidate gene & NOSIAP \\
\hline
\end{tabular}

personalized medicine. Howard MacLeod (University of North Carolina, Chapel Hill, USA) and Urs Meyer provided insights into the next challenges. The first is probably biostatistical. Tremendous efforts have been made to identify the association between genomic markers and drug-related phenotypes. However, association is not prediction. To provide meaningful insights, a test for disease risk needs to accurately identify positive cases and, at the same time, provide a low false positive rate. So far, very few of the identified pharmacogenomics markers meet these requirements and we are, therefore, still far from personalized medicine. Current markers can accurately identify sub-groups of high-risk patients but the predictive power to individualize risk remains weak. It is likely that the availability of thousands of human sequences combined with information on epigenetic variability (as presented by Magnus IngelmanSundberg, Karolinska Institute, Stockholm, Sweden) will explain some of the missing heritability and provide new genomic markers for pharmacogenomics. International collaborations and networks (such as the Global Alliance in Pharmacogenomics or the Pharmacogenetics Research Network-RIKEN collaboration) will contribute to larger scale studies. In the era of evidence-based medicine, the road to personalized medicine now depends on the development of biomarker assays that can identify patients at risk with high sensitivity and specificity. As drugs must prove themselves in clinical trials before they can be sold, the clinical relevance of genetic testing should be tested prospectively in adequately powered randomized studies. Because of the multifactorial nature of drug-related phenotypes, the development of global risk assessment scores based on traditional clinical risk factors, environmental and lifestyle factors, biological and genetics information should also be considered in order to increase predictive accuracy.

The second challenge is financial. On one hand, the direct costs for genetic testing have been decreasing in the past few years. The cost of genetic testing depends on the nature and complexity of the test but compares favorably to other biological or medical investigations. Some companies now offer DNA scans for less than $\$ 1,000$. On the other hand, as stated by various participants, very few studies have addressed the costeffectiveness of pharmacogenomics testing [13]. Evidence of cost-effectiveness, if provided, will obviously compel public authorities to promote personalized medicine, but it will also lead them to consider how to cover its costs. Finally, turning science into personalized healthcare will require important resources. Personalized medicine is entering what is classically called the 'valley of death', referring to the funding gap between a promised discovery and its commercial potential. Personalized medicine needs specific partners to get through this stage. Pharmaceutical companies, non-profit organizations, policy makers and healthcare communities should all collaborate to ensure pharmacogenomics information is translated into public health benefits.

We can also list several other challenges: the research funding dedicated to personalized medicine evaluation, the regulatory oversight, the reimbursement mechanisms in some healthcare systems, the need to improve the health-information infrastructure and the need to provide education and training for practitioners. All these are challenges and decisions that do not depend only on pharmacogenomics researchers.

For all these reasons, despite growing evidence for an influence of pharmacogenomics on medicine, the 
translation from bench to bedside is still an ongoing process. However, the new discoveries discussed at this meeting provide meaningful insights that will increase doctors' ability to personalize treatment in a not-toodistant future.

\section{Abbreviations}

GWAS, genome-wide association study.

Published: 22 February 2010

\section{References}

1. Wilkinson GR: Drug metabolism and variability among patients in drug response. N Engl J Med 2005, 352:2211-2221.

2. Meyer UA: Pharmacogenetics - five decades of therapeutic lessons from genetic diversity. Nat Rev Genet 2004, 5:669-676.

3. Pearson TA, Manolio TA: How to interpret a genome-wide association study. JAMA 2008, 299:1335-1344.

4. Shuldiner AR, O'Connell JR, Bliden KP, Gandhi A, Ryan K, Horenstein RB, Damcott CM, Pakyz R, Tantry US, Gibson Q, Pollin TI, Post W, Parsa A, Mitchell BD, Faraday N, Herzog W, Gurbel PA: Association of cytochrome P450 2C19 genotype with the antiplatelet effect and clinical efficacy of clopidogrel therapy. JAMA 2009, 302:849-857.

5. Collet JP, Hulot JS, Pena A, Villard E, Esteve JB, Silvain J, Payot L, Brugier D, Cayla G, Beygui F, Bensimon G, Funck-Brentano C, Montalescot G: Cytochrome $\mathrm{P} 4502 \mathrm{C} 19$ polymorphism in young patients treated with clopidogrel after myocardial infarction: a cohort study. Lancet 2009, 373:309-317.
6. Mega JL, Close SL, Wiviott SD, Shen L, Hockett RD, Brandt JT, Walker JR, Antman EM, Macias W, Braunwald E, Sabatine MS: Cytochrome p-450 polymorphisms and response to clopidogrel. N Engl J Med 2009, 360:354-362.

7. Simon T, Verstuyft C, Mary-Krause M, Quteineh L, Drouet E, Meneveau N, Steg $P G$, Ferrieres J, Danchin N, Becquemont L: Genetic determinants of response to clopidogrel and cardiovascular events. N Engl J Med 2009, 360:363-375.

8. Group SC, Link E, Parish S, Armitage J, Bowman L, Heath S, Matsuda F, Gut I, Lathrop M, Collins R: SLCO1B1 variants and statin-induced myopathy a genomewide study. N Engl J Med 2008, 359:789-799.

9. Hayden EC: Personalized cancer therapy gets closer. Nature 2009, 458:131-132.

10. Pouyanne P, Haramburu F, Imbs JL, Begaud B: Admissions to hospital caused by adverse drug reactions: cross sectional incidence study. French Pharmacovigilance Centres. BMJ 2000, 320:1036.

11. Mallal S, Phillips E, Carosi G, Molina JM, Workman C, Tomazic J, Jagel-Guedes E, Rugina S, Kozyrev O, Cid JF, Hay P, Nolan D, Hughes S, Hughes A, Ryan S, Fitch N, Thorborn D, Benbow A, Team P-S: HLA-B*5701 screening for hypersensitivity to abacavir. N Engl J Med 2008, 358:568-579.

12. Walko CM, McLeod H: Pharmacogenomic progress in individualized dosing of key drugs for cancer patients. Nat Clin Pract Oncol 2009, 6:153-162.

13. Cook J, Hunter G, Vernon JA: The future costs, risks and rewards of drug development: the economics of pharmacogenomics. Pharmacoeconomics 2009, 27:355-363.

doi:10.1186/gm13

Cite this article as: Hulot J-S: Pharmacogenomics and personalized medicine: lost in translation? Genome Medicine 2010, 2:13. 